\title{
GEGEVENS OMTRENT HET OP 31 AUGUSTUS 1923 \\ TE PARAMARIBO ONTHULDE STANDBEELD \\ VAN HARE MAJESTEIT DE KONINGIN, TER GELEGENHEID VAN HAAR ZILVEREN REGEERINGSJUBILEUM \\ DOOR
}

\section{FRED. OUDSCHANS DENTZ}

Ongeveer vijftien maanden voor den dag, waarop Hare Majesteit de Koningin haar zilveren regeeringsjubileum zou herdenken, richtte de voorzitter van de Koloniale Staten in Suriname, mr. S, D. de Vries een brief aan de nieuwsbladen, waarin hij o.a. mededeelde: „overtuigd van de verknochtheid en de liefde, welke in het volk van Suriname leven aan en voor het Oranje-Huis in het algemeen en Koningin Wilhelmina in het bijzonder, en gesterkt door de hooge instemming, welke het in deze door mij te nemen initiatief van de zijde van $Z$ ijne Excellentie den Gouverneur, Mr. A. J. A. A. Baron van Heemstra, in ruime mate mocht ondervinden, meen ik, dat ook Suriname niet mag en ook niet zal willen achterblijven in het medehuldigen van zijn Koningin". De heer De Vries stelde tevens daarin aan de redactie voor om, te zamen met haar en de andere door hem eveneens uitgenoodigde vertegenwoordigers der verschillende kerkgenootschappen, vereenigingen, instellingen en persorganen, op een nader te bepalen dag eene samenkomst te houden, teneinde te geraken tot het vormen van een herdenkingscomité.

Het algemeen huldigingscomité werd als volgt samengesteld:

Eerevoorzitter: mr. A. J. A. A. baron van Heemstra, gouverneur van Suriname; Voorzitter: mr. S. D. de Vries, voorzitter van de Koloniale Staten; leden: pater A. M. van Esch en J. Rodrigues, voor de Roomsch Katholieke gemeente; L. Schütz en J. N. Rijssel voor de Evangelische Broedergemeente; Ds. J. W. Poort, voor de Ned. Hervormde gemeente; J. A. Faverey voor de Evangelisch Luthersche gemeente; A. Fernandes voor de Ned. Port. Israëlietische gemeente; C. S. Pos, voor de Ned. Israëlietische gemeente; J. Blufpand voor de Vrije Evangelisatie; J. R. C. Gonggrijp, ondervoorzitter van de Koloniale Staten, R. D. Simons en E. R. de Vries leden van de Koloniale Staten; mr. L. J. Rietberg president van het Hof van Justitie; mr. J. 
L. Nysingh, procureur-generaal b/h Hof van Justitie; S. H. de Granada, agent-generaal; E. J. Kempees, directeur van v/h departement van openbare werken; H. L. Bierman, Majoor tit. Commandant der troepen; Th. E. Juda, majoor der Schutterij; A. F. C. Curiel, oudste consulaire vertegenwoordiger; mr. A. van Traa, voorzitter directeur der Surinaamsche Bank; C. J. A. Kwast, agent van de K.W.I.M.; W. H. A. Benz, voor de Kamer van Koophandel, S. Beck voor de vereeniging van Handel en Nijverheid; S. M. Levie, voor de vereeniging voor den grooten landbouw; D. S. Huizinga, voor de Surinaamsche landbouwvereeniging; mr. dr. P. H. W. G. van den Helm, voor het Algemeen Nederlandsch Verbond; J. G. Samson, voor de vereeniging voor nationale feesten; Fred. Oudschans Dentz, voor de vereeniging Oost en West; A. G. J. M. Alberga, voor den Algemeenen Plantersbond; Ch. C. Meriba voor de vereeniging van gouvernements bureauambtenaren, bond van belastingambtenaren, vereeniging van gevangenispersoneel en vereeniging van brievenbestellers; C. M. de Vries, voor het Surinaamsch Onderwijzersgenootschap; A. M. F. Oostburg, voor de onderwijzersvereeniging „Broederschap” en den bond van Surinamers in Nederland; F. A. J. Spong, voor de vereeniging van personeel v/h Militair Hospitaal; C. F. Getrouw, voor den Katholieken Onderwijzerskring; R. A. Schenkers, voor den Surinaamschen Politiebond; A. F. Schiff, voor de Vereeniging van Personeel Spoorwegen en Openbare Werken; J. Hendrison, voor de vereeniging van scheepsgezellen; J. Lindveld, voor de werkliedenvereeniging „Algemeen Welzijn"; Th. Bijlhout voor de vereeniging tot bevordering van Vakbelangen; G. Lichtveld, voor de R.K. Volksbond „St. Joseph” A. R. Louiszoon, voor den Surinaamschen Sjouwersbond; Sital Persad, voor de Britsch-Indische Immigrantenvereeniging; Djojowidigdo, voor de Ned.-Indische Immigrantenvereeniging; Ch. Law Hon, voor de Chineesche societeit „Kong Ngie Tong”; C. K. Kesler, voor de redactie van „De West” en A. J. Morpurgo, voor de redactie van „De Surinamer". Het comité belast met de dagelijksche leiding en uitvoering van zaken bestond uit de heeren: mr. S. D. de Vries, voorzitter, mr. A. van Traa, penningmeester, R. D. Simons, secretaris en ir. E. J. Kempees.

Het denkbeeld om een standbeeld voor Hare Majesteit op te richten ging uit van den eerevoorzitter en de gedane onderhandelingen in Nederland daarover werden aan het bijeengeroepen comité medegedeeld, dat zich daarbij neerlegde; alleen het lid Fred Oudschans Dentz opperde het voorstel tot de stichting van een fonds in den geest als het „Koning Willemfonds” in Londen.

De vervaardiging van het standbeeld werd opgedragen aan den heer A. G. van Lom te 's-Gravenhage. De oud-luitenant t/z P. J. Jager trad in Nederland als vertegenwoordiger van het comité op.

Een Oranjekleurige circulaire in twee talen, Nederlandsch en Negerengelsch, opwekkende tot geldelijken steun, werd in Suriname verspreid en inteekenlijsten werden rondgezonden.

In Suriname werd een bedrag van $f 18.578,02$ ontvangen. Particulieren droegen daartoe bij: $f 6.146,58^{1} / 2$, handelshuizen en 
winkeliers: $f 4.396$, verschillende vereenigingen en lichamen: $f 3.172,25$, de bevolkingsgroep Britsch-Indiërs: $f 212,50$, de Nederlandsch-Indiërs: $f$ 199,85 en de Chineezen: $f$ 408,50. Inzameling in de stad zelve bracht nog $f$ 489,81 op.

Ook buiten Paramaribo liet men zich niet onbetuigd.

De districten brachten de volgende bedragen bijeen: BenedenSuriname en Beneden-Para: $f 805,96$, Beneden-Commewijne: $f 760,06$, Boven-Suriname en Boven-Para: $f 736,85$, Nickerie: $f 459,58$, Coronie: $f 220,371 / 2$, Boven-Commewijne en Cottica: $f$ 211,70, Beneden- en Boven-Saramacca: $f$ 197,10 en Marowijne: $f 160,90$.

Het comité had bovendien nog een voordeelige post van $f 150,38$ aan den verkoop van platen met de beeltenis van H.M. de Koningin en de Koninklijke familie en van $f 47$ aan den verkoop van afgietsels van het standbeeld, zoodat de geheele som te zijner beschikking $f 18.775,40$ heeft bedragen.

De kosten van het standbeeld hebben bedragen $f 12.500$ aan den beeldhouwer, $f 1000$ aan een bronzen afgietsel ter hoogte van 50 c.M. voor H. M. de Koningin benevens gipsafgietsels, $f 1.054,65$ aan werkloonen en materialen ten behoeve der opstelling. Voorts werd nog uitgegeven aan onthullingskosten, t.w. onkosten van inrichting en versiering van het terrein op 31 Augustus 1923, alsmede onthaal van schoolkinderen welke daarbij zongen, doek voor onthulling, vlaggen en bloemen: $f 429,52$, giften aan de melaatscheninrichtingen „Bethesda”, „Gerardus Majella” en „Groot Chatillon" ten behoeve van een tractatie aan verpleegden: $f 300$, postzegels en telegrammen: $f 148,391 / 2$, algemeene onkosten in Suriname en Nederland, alsmede kosten der collecten op 29 en 30 April, photo's, administratie- en reiskosten : $f 270,75$, tezamen $f 15.703,31^{1} / 2$.

Er bleef derhalve een batig saldo van $f 3.072,081 / 2$.

De eerste vergadering van het huldigingscomité had plaats op Donderdag 20 Juli 1922, de laatste op Zaterdag 17 April 1926, toen het werd ontbonden na rekening en verantwoording te hebben afgelegd. Daarbij werd besloten, dat van het vorenvermeld saldo, inmiddels verminderd tot $f 2722$, een bedrag van $f 1000$ zou worden bestemd voor het aanbrengen van een nieuw voetstuk onder het standbeeld. Aan elk der drie melaatscheninrichtingen zou $f 500$ worden geschonken, terwijl de vereeniging „Het Groene Kruis” het overblijvende of $f 222$ zou ontvangen.

De aanbieding aan Hare Majesteit de Koningin van het ongeveer $1 / 2 \mathrm{M}$ hooge bronzen afgietsel van het standbeeld had op 21 Maart 1925 plaats door een deputatie, het Surinaamsche huldi- 
gingscomite vertegenwoordigende en bestaande uit de heeren: dr. H. D. Benjamins, professor P. C. Flu, D. Coutinho en P. J. Jager. De aanbieding ging vergezeld van een oorkonde en eenige foto's. Dr. Benjamins hield daarbij de volgende rede:

Majesteit,

Het zij mij veroorloofd eerbiedig een woord tot $U$ te richten.

Het Huldigingscomité in Suriname heeft ons vereerd met de uitnoodiging om aan Uwe Majesteit aan te bieden de nu eerst gereed gekomen verkleinde reproductie in brons van het standbeeld van Uwe Majesteit, door een Nederlandsch kunstenaar vervaardigd en sedert 31 Augustus het Gouvernementsplein te $\mathrm{Pa}$ ramaribo sierende.

De trouwe liefde van Suriname's bevolking voor haar Vorstin heeft zich bij elke gebeurtenis in het Koninklijke gezin ondubbelzinnig geuit.

Het beeld van Koningin Wilhelmina heeft steeds geleefd in de harten der bevolking. Maar zij wenschte dat beeld ook steeds voor oogen te hebben. Het was dan ook een gelukkig denkbeeld van het Huldigingscomité, met zijn eere-voorzitter Gouverneur Van Heemstra, om de herinnering aan het 25-jarig jubileum van Uwer Majesteits regeering, levendig te houden door de oprichting van dit monument, een denkbeeld, dat dadelijk bijval vond bij de geheele bevolking.

Voor het Comité dat met groote toewijding zijn taak heeft vervuld moet het een streelende voldoening zijn, iets tot stand te hebben gebracht dat van geslacht tot geslacht aan de bevolking dierbaar zal zijn, als symbool van hare verknochtheid aan Uw Huis.

Ik zal niet herhalen al wat zoo goed gezegd is bij de onthulling van het standbeeld, in het telegram van hulde van den Gouverneur, in het adres der Koloniale Staten, in de talrijke adressen van eerbiedige hulde van de burgerij, die Uwe Majesteit hebben bereikt en in de gedenkboeken en tijdschriften en in de Surinaamsche bladen.

Slechts dit wil ik herhalen, dat in geen tijdperk van de geschiedenis van Suriname, zoowel op geestelijk als op stoffelijk gebied door het Moederland zooveel is gedaan voor de kolonie als gedurende het 25-jarig tijdperk van Uwer Majesteits regeering. Dat de maatregelen op economisch gebied niet altijd het gewenschte gevolg hebben gehad, is toe te schrijven aan oorzaken waartegen de mensch niets vermag.

De grondwetsherziening van 1922 opent ook voor dit over- 
zeesch gebiedsdeel van Uwer Majesteits Rijk nieuwe perspectieven.

Waren het bij de inhuldigingsfeesten in de kolonie klanken van liefde en trouw aan de Vorstin, welke vernomen werden, bij uw zilveren feest voegden zich daarbij uitingen van innige dankbaarheid voor al hetgeen onder de regeering van Uwe Majesteit voor de kolonie is gedaan.

Aan de voorzijde van het monument prijkt het Koninklijk wapen, met zijn fier: Je Maintiendrai. Op de achterzijde het oude Surinaamsche wapen met zijn spreuk: Justitia, Pietas, Fides. Gouverneur van Heemstra heeft het zoo treffend gezegd in het jubileumnummer van het blad De Surinamer, dat deze spreuk Koningin Wilhelmina kenmerkt, zoowel in Haar wezen als in Hare regeering.

Het is de innige bede van Suriname's bevolking, dat Uwe Majesteit met haar gezin nog gedurende een lange reeks van gelukkige jaren moge gespaard blijven.

Majesteit! moge het U gegeven zijn in de ingetreden regeeringsperiode Suriname, dat niets liever wenscht dan Nederlandsch te blijven, te zien worden een bloeiend en gelukkig land, een parel aan Uw Kroon.

Hare Majesteit antwoordde hierop met een korte toespraak, waarin zij uitdrukking gaf aan hare gevoelens van groote erkentelijkheid voor de liefde en trouw van Suriname's bevolking aan haar en haar gezin. De wenschen en belangen van Suriname's bevolking, zouden bij haar steeds een open oor vinden. Het grootsche huldeblijk der bevolking had haar getroffen. $\mathrm{Zij}$ verzocht haar hartgrondigen dank te willen overbrengen. Ten slotte sprak Hare Majesteit den wensch uit, dat zij het nog mocht beleven, dat de wenschen van voorspoed en geluk voor Suriname's bevolking, geuit door dr. Benjamins, zullen worden verwezenlijkt.

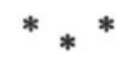

In het voorgaande is in het kort de geschiedenis van het op 31 Augustus 1923 op het Gouvernementsplein te Paramaribo onthulde standbeeld vastgelegd.

$\left.{ }^{1}\right)$ De geschiedenis van het huldeblijk aan H. M. aangeboden ter gelegenheid van Hoogstderzelver huwelijk op 7 Februari 1901 is te vinden in afl. 7 en 8 van den 69sten jaargang van „De Navorscher” (1920) door Fred. Oudschans Dentz. 